\title{
Modelling transpiration of soilless greenhouse cucumber and its relationship with leaf temperature in a mediterranean climate
}

\author{
Georgios Nikolaou“*, Damianos Neocleous², Nikolaos Katsoulas', Constantinos Kittas ${ }^{1}$ \\ ${ }^{1}$ Department of Agriculture Crop Production and Rural Environment, School of Agricultural Sciences, University of Thessaly, Fytokou Street, \\ Volos, Magnesia 38446, Greece, ${ }^{2}$ Department of Natural Resources and Environment, Agricultural Research Institute, 1516 Nicosia, Cyprus
}

\section{A B S T R A C T}

\begin{abstract}
Three experiments (spring and autumn-winter seasons) with soilless cucumber crop (cv. Phenomeno) were conducted in order: (i) to calibrate the simplified Penman -Monteith model equation as affected by greenhouse microclimate (ii) to validate the prediction efficiency of the model at different climatic conditions and (iii) to establish a relationship between transpiration and leaf temperature. To determine PenmanMonteith model parameter variables related to the plants such as transpiration and leaf area index (LAI), so as environmental variables (i.e., radiation, temperature, humidity) were recorded. The results revealed that the determined model parameters were suitable for the whole cucumber cultivation cycle and a wide range of climatic conditions. However, parameterization of the model using autumn-winter crop data revealed superiority compared to spring data, as indicated by the correlation coefficients. Model validation showed a good fit between simulates and measures allowing implementation in commercial soilless practices. With respect to greenhouse microclimate, cooling affected daily mean air temperature and vapor pressure deficit, so as model coefficients. Leaf temperature indicated a good correlation with transpiration and the prediction equation was validated under different greenhouse climatic conditions. These results may be of value in Mediterranean greenhouses, enabling a more efficient water resource management without significant losses in agricultural productivity.
\end{abstract}

Keywords: Cucumis sativus; Fan and pad cooling system; Stem variation; Lysimeter; Model coefficients

\section{INTRODUCTION}

Measurement of crop evapotranspiration is an essential tool to determine the irrigation requirements in plants (Liu et al., 2008; Razzak et al., 2016). In substrate culture, irrigation control requires the measurement of transpiration over short time intervals, e.g. in an hourly basis or even less (Carmassi et al., 2013). This can therefore aid in the efficient delivery of water and fertilizer supply, especially in areas with a Mediterranean climate, where water is often a scarce natural resource (Rouphael et al., 2004; Feng et al., 2017).

Indirect measurements of plant water consumption using radiation or energy balance models, weather data correlation (i.e., temperature, humidity, radiation) and plant related characteristics (i.e., leaf area index, leaf temperature, leaf aerodynamic and stomata resistances) with water use, have been proved helpful in irrigation control in soilless production systems (Morille et al., 2013). However, this type of control should be continually checked and calibrated according to greenhouse microclimates, plant species and crop stages as they were initially developed and calibrated under different environmental conditions, e.g. areas with low values of leaf temperatures and solar radiation (i.e., Stanghellinis model) or within greenhouses which were generally poorly ventilated during a large part of the growing season (Boulard and Wang, 2000). In addition, in the last decades several studies have been conducted, focused on different greenhouse microclimates as it affected by cooling or different ventilation rates in order to evaluate the best model for predicting real time transpiration along with different irrigation strategies (e.g. Baille et al., 1994; Luo et al., 2005; Katsoulas et al., 2006; Tsirogiannis et al., 2010; Villarreal-Guerrero et al., 2012). The majority of these studies use a variety of evapotranspiration models

\footnotetext{
*Corresponding author:

Georgios Nikolaou, Department of Agriculture Crop Production and Rural Environment, School of Agricultural Sciences, University of

Thessaly, Fytokou Street, Volos, Magnesia 38446, Greece. Mobile: 357 99582206. E-mail: gnicolaounic@gmail.com

Received: 27 January 2017; Revised: 29 Novmber 2017; Accepted: 05 December 2017; Published Online: 14 December 2017
} 
originally developed by Penman-Monteith equation (Schröder and Lieth, 2002).

For example, the simplified form of Penman-Monteith equation allows the prediction of the actual evapotranspiration rate by overcoming difficult to measure variables of the plants, i.e., leaf resistances, with a good level of accuracy using commonly measured weather data (Baille et al., 1994). Thus, many researchers successfully used the simplified Penman-Monteith method for estimating transpiration for several ornamental and horticultural greenhouse crops (Baille et al., 1994; Kittas et al., 1999; Pollet et al., 2000; Montero et al., 2001; Rouphael et al., 2004). However, the accuracy of the model is crop specific and depends a lot on the microclimate of the greenhouse (Fazlil-Ilahi, 2009). In this context, a number of researches, investigated the simplified form of Penman-Monteith method on soilless cucumber crop as affected by different climatic conditions, concluding that optimizing model efficiency is often complicated as model coefficients depends on the crop and even within the same species, growth characteristics may differ among cultivars and may change over time and prevailing environmental conditions (Yang et al., 1990; De Graaf and Esmeijer, 1998; Medrano et al., 2005; JuarezMaldonado et al., 2014). This means that direct measurement of transpiration with the use of lysimeters can be used on plants actual water consumption with the aim of model calibration as weight changes in mass could be one of the most accurate and quantity measures over shorter intervals (Meijer et al., 1985; Beeson, 2011; Schmidt et al., 2013).

In any case of monitoring irrigation, especially within high value horticultural crops, physiological plant based measurement, which fits within the "speaking plan" approach, should be better implemented, as they could provide important supplementary data of plant responses in real time, such as changes in leaf temperature or stem shrinkage or expansion (Helmer et al., 2005; Steppe et al., 2008; Fulcher et al., 2012; Zhao et al., 2016). Therefore the early detection of plant physiological disorder caused by improper irrigation could be to monitor, allowing adjustment or validation of irrigation regimes such as the volume and timing of irrigation (Ton and Kopyt, 2003).

Even though in the field of modelling transpiration a lot of work is being done, to the authors' best knowledge, there is space for improvement as far as the prediction of irrigation, it's based on plants' actual responses of changes in plant water status, instead of measuring greenhouse climate conditions enabling a more efficient water resource management especially in areas with scarce water resources.

In view of the above, the objectives of this work were (a) the calibration of a simplified form of Penman-Monteith model in soilless cucumber crop as affected by greenhouse microclimate (cooling), (b) the validation of the model under different growing conditions than those estimated and (c) to establish a relationship between transpiration and a plant indicator input (i.e. leaf temperature) as an alternative to predict transpiration.

\section{MATERIALS AND METHODS}

Three experiments were carried out in an East-West, three spans, polyethylene - covered greenhouse at the Agricultural

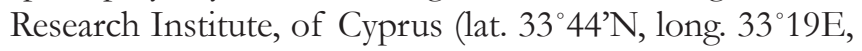
alt. five meters). The first experiment was conducted from March to June 2014 (spring crop; SP), the second from October to December 2014 (autumn-winter crop; AW) and the third from March to June 2015 (spring crop; SP).

During the 2014 SP experimental period two different irrigation frequencies $0.288 \mathrm{Kg} \mathrm{m}^{-2}$ [Medium Irrigation Frequency (MIF)] and $0.448 \mathrm{Kg} \mathrm{m}^{-2}$ [Low Irrigation Frequency (LIF)] were applied, as practised by the local growers, in order to establish a relationship between transpiration and plant responses (i.e. leaf temperature, stem variations), as affected by different irrigation frequencies in soilless cucumber crop. The proposed transpiration model was then tested during the 2014 AW and 2015 SP experimental period in a greenhouse compartment with and without cooling (hereafter referred to as $\mathrm{C}$ and $\mathrm{NC}$ ), additionally with the calibration and validation of the simplified form of Penman-Monteith model.

\section{Greenhouse facilities}

The geometrical characteristics of the greenhouse were as follows: eaves height $3.50 \mathrm{~m}$, ridge height five meters, spans width seven meters, total length $24 \mathrm{~m}$, ground area $504 \mathrm{~m}^{2}$, volume $2016 \mathrm{~m}^{3}$. The greenhouse was equipped with a single continuous roof vent in the middle span and side vents for natural ventilation. The roof vent were $24 \mathrm{~m}$ long and one meter wide with a maximum opening area of $24 \mathrm{~m}^{2}$, whereas the side vent were $18 \mathrm{~m}$ long and 2.20 $\mathrm{m}$ wide with a maximum opening area equal to $52.8 \mathrm{~m}^{2}$. The greenhouse was used during the 2014 SP experimental period and then separated into two compartments with and without cooling (fan and pad system). In the noncooling compartment dynamic ventilation by a single span operated, in daytime when the temperature exceeded $33^{\circ} \mathrm{C}$ and at night, when relative humidity exceeded $75 \%$. In the compartment with cooling, dynamic ventilation was performed by two fans, one at each span (air flow rate for each fan was $\left.31500 \mathrm{~m}^{3} \mathrm{~h}^{-1}\right)$ when the greenhouse temperature exceeded $24^{\circ} \mathrm{C}(\mathrm{AW})$ and $25^{\circ} \mathrm{C}(\mathrm{SP})$ and the cooling system operated when the temperature exceeded $25^{\circ} \mathrm{C}(\mathrm{AW})$ and $26{ }^{\circ} \mathrm{C}(\mathrm{SP})$. 
Plant material, irrigation system schedule and control Cucumber plants $(\mathrm{n}=360)$ (Cucumis sativus L. cv Phenomenon) which had been raised in rockwool started cubes $(10 \mathrm{~cm} \mathrm{x}$ $10 \mathrm{~cm}$ x $6.5 \mathrm{~cm}$ ), were transplanted on 2nd April 2014, on 2nd October 2014 and on 17th March 2015, in rockwool slabs $(100 \mathrm{~cm} \times 20 \mathrm{~cm} \times 7.5 \mathrm{~cm}$ ) (Grodan Company; Denmark), for AW and SP crops, resulting in a plant density of 1.6 plant $\mathrm{m}^{-2}$. The plants were supported by plastic twine attached $2.2 \mathrm{~m}$ above the plant row on a horizontal wire and trained to one stem per plant by pruning all auxiliary shoots and continuous removal of old or damaged leaves. During the 2014 SP experimental period, two different irrigation doses and application frequency treatments were followed on a number of every 180 plants. Irrigation control for the first 14 days after transplanting was performed with $0.24 \mathrm{Kg} \mathrm{m}^{-2}$ periodically at fixed time intervals as per usual practices by local growers. Eventually, the irrigation frequency was based on solar radiation as described by Katsoulas et al. (2006) and performed whenever accumulated solar radiation energy outside the greenhouse reached 1.9 $\mathrm{MJ} \mathrm{m}^{-2}$ (MIF) and $3.0 \mathrm{MJ} \mathrm{m}^{-2}$ (LIF). The amounts of water applied per irrigation event were $0.288 \mathrm{Kg} \mathrm{m}^{-2}$ (MIF) and $0.448 \mathrm{Kg} \mathrm{m}^{-2}$ (LIF). The total daily amount of water applied was equal for the two treatments. Night time irrigation was also performed to avoid substrate dryness in all cases. Complete nutrient solutions were applied in all irrigation events. Nutrient solution compositions were based on recommendations by Savvas et al. (2013).

During the 2014 AW and 2015 SP, the number of plants in the greenhouse compartment without cooling was 120, and in the compartment with cooling 240 as shown in Fig. 1. The irrigation system and design followed the same layout as the 2014 SP experiment and irrigation frequency was performed whenever accumulated solar radiation energy outside the greenhouse reached $1.8 \mathrm{MJ} \mathrm{m}^{-2}$. The irrigation dose was $0.288 \mathrm{Kg} \mathrm{m}^{-2}$ in both treatments, similarly as used at 2014 SP (MIF) treatment, in order to maintain drainage volumes of $35-40 \%$.

\section{Crop monitoring}

One representative plant in MIF and LIF treatment was monitored by means of a Phyto Sensor system as an attempt of reformulation of the simplified form of Penman-Monteith transpiration model by using plant indicators. The plant sensors were a leaf temperature sensor (Model LT-1z), a stem micro-variation sensor (Model SD-5z) and a substrate temperature sensor (Model SMTE3z). Data was sent wirelessly to the main system unit, phyto-Logger with micro SD card and received to a PC. Sensors were purchased from Bio Instruments Company, Chisinau, Moldova. Data was collected every 10 minutes, and linear regression models were developed between leaf temperature and solar radiation and vapor pressure deficit.

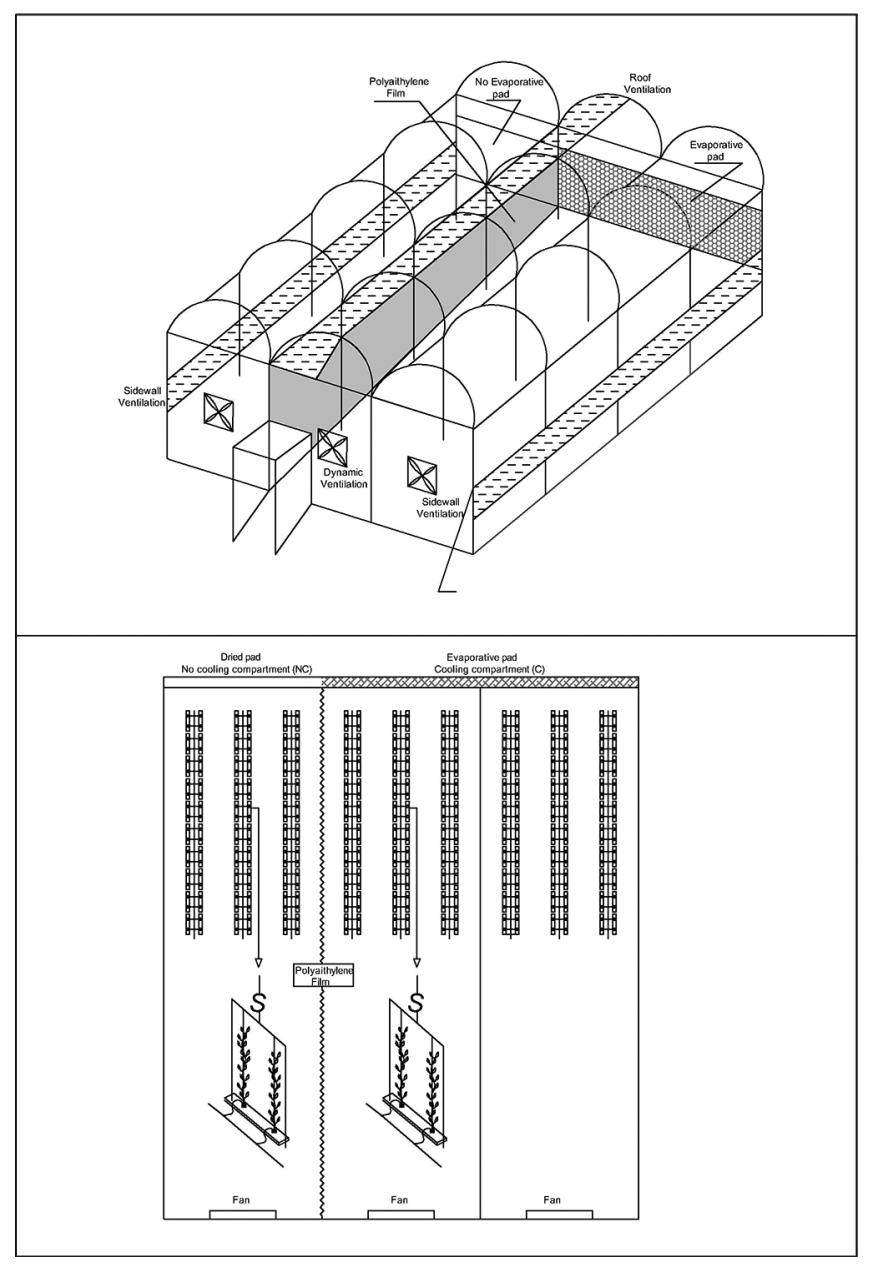

Fig 1. Schematic description of the separation of greenhouse in the two compartments, positioning of plant material and measuring equipment (lysimeters).

During the following experimental periods, 2014 AW and 2015 SP, the same phyto-sensors were used as an attempt of model validation.

\section{Data recorder and measurements}

Outside greenhouse weather data, i.e., air temperature $\left(\mathrm{Ti},{ }^{\circ} \mathrm{C}\right.$ ), relative humidity $(\mathrm{RH}, \%$ ) (Sensor type PT 100; Galcon, Kfar Blum, Israel) and net solar radiation $\left(\mathrm{R}_{\mathrm{Go}}, \mathrm{W} \mathrm{m}^{-2}\right.$ ) (Sensor pyranometer type TIR-4P; Bio Instruments Company, Chisinau, Moldova) were recorded. Sensors of the same type were used for monitoring climatic variables within each greenhouse compartment. All measurements were recorded on a data logger system (Galileo controller; Galcon, Kfar Blum, Israel). Data was recorded at 30 second intervals and a ten minute average was estimated.

Plant transpiration was monitored, by a weighting lysimeter consisting of a load cell "S type" (Model 9363; Vishay Precision Group, Malvern, USA) mounded from the greenhouse ceiling to a plant supporting system with a 
growing media of two plants in each treatment during the period of experiments. The cell had a capacity of $50 \mathrm{Kg}( \pm 0.02 \mathrm{~g})$. The weight loss measured by the electronic balance was assumed to be equal to crop transpiration. Drainage water was automatically collected and measured from the lysimeter; these determinations were made daily at the same time.

Plant destructive measurements over plant growth cycle were repeated five times in order to calculate leaf area index (LAI: $\mathrm{m}^{2}$ leaf $\mathrm{m}^{-2}$ ground) in all crops by means of a scanner (F4280; HP, Deskjet, Japan). In all treatments four plants were randomly chosen on the 15, 30, 45, 60 and 75 days after transplanting (DAT) for the 2014 SP on the 13, 23, 33, 43 and 53 for the 2014 AW crop and on the $15,29,44,59$ and 74 DAT for the 2015 SP crop. To calculate the leaf area, a software was applied to leaf scanned images according to Varma and Osuri (2013). The plants removed for destructive measurements were replaced by buck up plants of the same size.

\section{The simplified form of Penman-Monteith equation}

For the calibration of model coefficients, i.e., A and B parameters in the simplified form of Penman-Monteith transpiration model; the following formula was used (Baille et al., 1994; Medrano et al., 2005):

$\lambda T=A(1-\exp (-K L A I)) G+B L A I V P D$

Where $\mathrm{T}$ is the measured crop transpiration rate $\left(\mathrm{kg} \mathrm{m}^{-2} \mathrm{~s}^{-1}\right), \mathrm{G}$ the measured inside greenhouse solar radiation ( $\left(\mathrm{W} \mathrm{m}^{-2}\right)$, VPD the calculated inside air vapor pressure deficit $(\mathrm{kPa})$, LAI the calculated leaf area index ( $\mathrm{m}^{2}$ leaf $\mathrm{m}^{-2}$ ground), $\mathrm{K}$ is the light extinction coefficient which was taken from the literature $(0.86$ and 0.63 for the autumn and spring cycle) following Medrano et al. (2005), $\lambda$ the vaporization heat of water $\left(\mathrm{J} \mathrm{kg}^{-1}\right)$, and $A$, $B$ values of equation parameters (A, dimensionless; $B$, $\left.\mathrm{W} \mathrm{m} \mathrm{mPa}^{-1}\right)$. The model was run for daylight hours with mean values of recording data every 30 minutes for inside solar radiation greater than $50 \mathrm{~W} \mathrm{~m}^{-2}$.

The model was calibrated at different greenhouse environmental conditions ( $\mathrm{C}$ and NC) at 2014 AW and 2015 SP and then, model coefficients as estimated were tested as an attempt of validation, between different growing periods.

\section{Statistical analysis}

Selected data was analyzed and comparisons of means were tested using ANOVA by using a Statistical Package for the Social Sciences (IBM Corp. Released 2011. IBM SPSS Statistics for Windows, Version 20.0. Armonk, NY: IBM Corp).

\section{RESULTS AND DISCUSSION}

\section{Climate and plant data}

Greenhouse environmental parameters were affected by the operation of the cooling system (2014 AW-2015 SP), with profound differences between compartments during the SP period, as higher external temperature and radiation levels were observed (Tables 1 and 2). Particularly, the mean air temperature from 10:00 to 14:00 $\mathrm{h}$ was higher for the no-cooling (NC) trial by $4.88^{\circ} \mathrm{C}(\mathrm{AW})$ and $7.42{ }^{\circ} \mathrm{C}(\mathrm{SP})$ comparing with the cooling trial (C) and by $0.48 \mathrm{kPa}$ (AW) and 1.1 (SP) of mean vapor pressure deficit (VPD). Fig. 2 shows the evolution of daily mean air temperature over time and estimated values of VPD for six representative day period (DAT 40-45) as affected by cooling for (AW) and $(\mathrm{SP})$ period.

The daily variation of the mean measured canopy transpiration rate $\left(\mathrm{W} \mathrm{m}^{-2}\right)$ is presented in Fig. (3). It can be observed that transpiration was higher under no cooling conditions in both crop cycles; with greater differences between compartments found during high solar radiation (SP) period (Table 3). During 50-55 DAT higher transpiration values of $33 \%$ at (AW) and $55 \%$ at (SP) were observed in the $(\mathrm{NC})$ treatment compared with the $(\mathrm{C})$.

Irrespectively of the growing season, LAI of plants in the $\mathrm{NC}$ trial was higher during the whole cropping period. The mean values of leaf area index of treatments for (2014 autumn-winter crop; AW) and (2015 spring crop; SP) are presented in Table 4.

The higher values of LAI during the AW period in comparison with the SP period are resulting from higher air humidity values inside greenhouse which seems to stimulate cucumber leaf growth as also reported in a previous paper by Körner and Challa (2003). However, higher values of LAI observed in the AW period were not able to explain lower transpiration values comparing with the SP period. Similarly, Yang et al. (1989) did not find a strong relationship between transpiration and LAI in the cucumber crop. It is clear from the results that the effect of greenhouse climatic parameters (i.e., VPD, air temperature, solar radiation values) on transpiration rate were stronger, as higher values observed in the no-cooling (NC) trial during the SP growing period compared with the same replications in the evaporative cooling; or in AW period (Kittas, 1990; Zi-Kun et al., 2010).

Model calibration of the simplified form of Penman-Monteith equation

In order to determine $\mathrm{A}$ and $\mathrm{B}$ model coefficients in the simplified form of Penman -Monteith equation Eq. (1), linear regression model was used to fit the experimental 
Table 1: Mean values ( \pm standard deviation) of inside microclimate greenhouse (from 10:00 h to 14:00 h) for (2014 autumn-winter crop; AW) and (2015 spring crop; SP)

\begin{tabular}{|c|c|c|c|c|c|c|}
\hline \multirow[b]{3}{*}{ DAT } & \multicolumn{3}{|c|}{ Compartment without cooling } & \multicolumn{3}{|c|}{ Compartment with cooling } \\
\hline & \multicolumn{6}{|c|}{ AW } \\
\hline & $\mathrm{T}_{\mathrm{i}}\left({ }^{\circ} \mathrm{C}\right)$ & $\mathrm{RH}_{\mathrm{i}}(\%)$ & $\mathrm{VPD}_{\mathrm{i}}(\mathrm{kPa})$ & $\mathrm{T}_{\mathrm{i}}\left({ }^{\circ} \mathrm{C}\right)$ & $\mathrm{RH}_{\mathrm{i}}(\%)$ & $\mathrm{VPD}_{\mathrm{i}}(\mathrm{kPa})$ \\
\hline $1-15$ & $32.1(1.8)$ & $49.2(3.8)$ & $2.5(0.4)$ & $30.2(4.4)$ & $57.1(13.3)$ & $1.9(0.9)$ \\
\hline $16-31$ & $30.6(2.9)$ & $56.6(11.1)$ & $2.0(0.5)$ & $24.7(1.9)$ & $60.7(8.1)$ & $1.2(0.3)$ \\
\hline $34-45$ & $27.9(4.7)$ & $69.7(12.5)$ & $1.3(0.7)$ & $21.8(2.4)$ & $64.6(15.2)$ & $1.0(0.5)$ \\
\hline $46-60$ & $27.7(4.1)$ & $68.1(9.1)$ & $1.3(0.5)$ & $21.8(2.3)$ & $66.9(9.7)$ & $0.9(0.3)$ \\
\hline $61-72$ & $27.0(3.6)$ & $67.7(8.2)$ & $1.2(0.4)$ & $22.4(1.4)$ & $67.1(9.1)$ & $0.9(0.3)$ \\
\hline \multicolumn{7}{|c|}{ SP } \\
\hline $1-15$ & $30.3(4.3)$ & $40.7(12.3)$ & $2.7(0.8)$ & $23.2(2.2)$ & $45.7(1.1)$ & $1.6(0.4)$ \\
\hline $16-31$ & $32.2(2.1)$ & $46.1(10.7)$ & $2.7(0.7)$ & $23.6(1.1)$ & $46.5(8.9)$ & $1.6(0.3)$ \\
\hline $34-45$ & $32.4(2.9)$ & $48.1(12.9)$ & $2.6(0.8)$ & $24.2(2.2)$ & $48.1(9.8)$ & $1.6(0.4)$ \\
\hline $46-60$ & $33.2(3.6)$ & $49.7(6.4)$ & $2.6(0.4)$ & $26.2(1.4)$ & $55.1(5.5)$ & $1.5(0.3)$ \\
\hline $61-75$ & $34.1(2.0)$ & $45.6(8.6)$ & $3.0(0.8)$ & $27.9(2.0)$ & $54.2(6.9)$ & $1.8(0.4)$ \\
\hline
\end{tabular}

$\mathrm{T}_{\mathrm{i}}$ : greenhouse air temperature $\mathrm{RH}_{\mathrm{i}}$ : greenhouse air relative humidity; $\mathrm{VPD}_{\mathrm{i}}$ : greenhouse air vapor pressure deficit; DAT: days after transplanting.

Table 2: Mean values ( \pm standard deviation) of solar radiation and outside greenhouse climatic data (daylight) for (2014 autumn-winter crop; AW) and (2015 spring crop; SP)

\begin{tabular}{|c|c|c|c|c|}
\hline \multirow[b]{3}{*}{ DAT } & \multicolumn{4}{|c|}{$\begin{array}{l}\text { Outside greenhouse climatic data and inside solar } \\
\text { radiation }\end{array}$} \\
\hline & \multicolumn{4}{|c|}{ AW } \\
\hline & $R G_{1}\left(W^{-2}\right)$ & $R G_{0}\left(W^{-2}\right)$ & $\mathrm{T}_{0}\left({ }^{\circ} \mathrm{C}\right)$ & RHo (\%) \\
\hline $1-15$ & $346(183.1)$ & $545(285.3)$ & $29.3(4.2)$ & $55.0(9.8)$ \\
\hline $16-31$ & 274 (178.3) & $436(273.4)$ & $26.4(4.1)$ & $58.4(12.5)$ \\
\hline $34-45$ & 235 (165.2) & $383(250.1)$ & $22.6(4.2)$ & $60.8(18)$ \\
\hline $46-60$ & $198(144.9)$ & $338(235.4)$ & $19.9(4.8)$ & $63.9(14.8)$ \\
\hline $61-72$ & $172(122.6)$ & $293(199.4)$ & $21.2(3.5)$ & $72.0(11.5)$ \\
\hline \multicolumn{5}{|c|}{ SP } \\
\hline $1-15$ & $374(219.2)$ & $545(314.8)$ & 20.7 (3.6) & $57.8(13.5)$ \\
\hline $16-31$ & $422(235.2)$ & 607 (337.7) & $21.0(4.5)$ & $57.4(13.6)$ \\
\hline $34-45$ & 472 (229.3) & 678 (329.3) & 23.7 (5.3) & $60.2(13.7)$ \\
\hline $46-60$ & 491 (202.8) & 705 (319.9) & $26.2(3.7)$ & $62.0(16.6)$ \\
\hline $61-75$ & $509(224.7)$ & 731 (322.7) & $28.9(4.3)$ & $51.4(13.4)$ \\
\hline
\end{tabular}

$\mathrm{RG}_{\mathrm{i}}$ : inside greenhouse solar radiation; $\mathrm{RG}_{0}$ : outside greenhouse solar radiation; $\mathrm{T}$ : outside greenhouse air temperature; $\mathrm{RH}_{0}$ : outside greenhouse air relative humidity; DAT: days after transplanting

climate and plant data. The influence of cooling (C) on the calibration of the simplified Penman-Monteith equation indicates a reduction in coefficient $\mathrm{A}$ more than $40 \%$ and an increase of B coefficient more than $25 \%$ compared to the NC trial (Table 5). Particularly the coefficient estimated for values $\mathrm{A}$, range from 0.10 to 0.45 (dimensionless) with lower values observed within the cooling compartment $(C)$ and $\mathrm{B}$ values from 11.05 to $50.23 \mathrm{~W} \mathrm{~m} \mathrm{WPa}^{-1}$ with lower values observed at the compartment without cooling (NC). Similarly, Medrano et al. (2005) reported values of A 0.24 and $\mathrm{B}$ from 22.0 to $37.6 \mathrm{~W} \mathrm{~m}^{-2} \mathrm{kPa}^{-1}$ for a cucumber crop grown at low and high radiation levels.

\section{Model validation of the simplified form of Penman-Monteith equation}

Model coefficients, i.e., A and B values, were estimated from the AW experimental data and then were tested according to Eq. (1) for the estimation of transpiration during the SP period and vice versa. Subsequently, calculated transpiration was compared with measured transpiration at different climatic conditions than those estimated as an attempt of validation. The coefficient of determination $\left(R^{2}\right)$ of a linear relationship between estimated and measured transpiration values, for both $(\mathrm{NC})$ and $(\mathrm{C})$ was $0.733(\mathrm{n}=294)$ and 0.775 $(\mathrm{n}=318)$ respectively when the model was parameterized with AW data (Fig. 4). On the other hand, when the model was parameterized using SP experimental data, results were unsatisfactory, with greater scattering between measured and calculated values as indicated by the low determination coefficients that were $0.228(\mathrm{NC})$ and 0.312 for $(\mathrm{C})$ for a number of observation 366 in both cases (Fig. 4).

Our results show that the simplified Penman-Monteith model is suitable to predict cucumber water requirements within a short time basis. It was found that estimated values of the model parameters A and B were different between growing periods and even within the same, as affected by the operation of a cooling system.

Despite differences, parameters A and B obtained during the AW trial, could be used for irrigation control of greenhouse soilless cucumber, as the model gives similar results of the canopy transpiration results with respect to the measured value, in a different growing period of a year, in greenhouse with or without evaporative cooling system.

\section{Predictors of transpiration and model reformulation}

Linear regression modelling with the transpiration rate (W $\mathrm{m}^{-2}$ ), as a depended variable was developed for two different irrigation frequency treatments of $0.288 \mathrm{Kg} \mathrm{m}^{-2}$ and $0.448 \mathrm{Kg} \mathrm{m}^{-2}$ with several predictors related plant (i.e. leaf temperature, stem variation), environment (i.e. incoming solar radiation, VPD) and substrate temperature. As results indicated they are shown to be significant for 

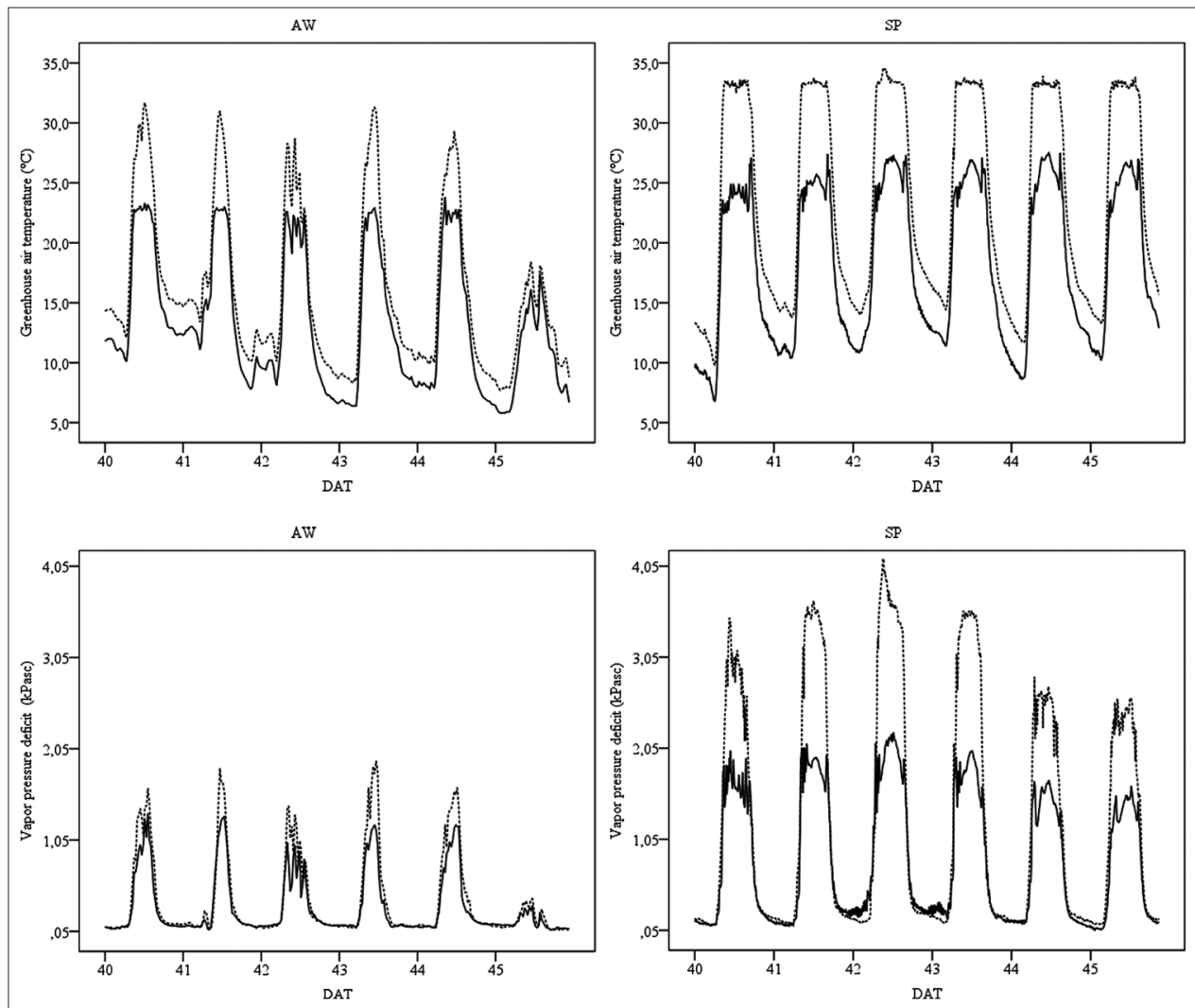

Fig 2. Greenhouse air temperature during a six days period (DAT 40-45) inside the two greenhouse compartments for (2014 autumn-winter crop; AW, no cooling -NC, cooling-C), upper left side and (2015 spring crop; SP, no cooling-NC, cooling- C), upper right side and air vapor temperature (DAT 40-45), (no cooling-NC, cooling-C) for (2014 autumn-winter crop; AW), bottom left side and (2015 spring crop; SP), bottom right side. Dotted line stands for NC greenhouse compartment and continuous line for $\mathrm{C}$ greenhouse compartment in all cases.
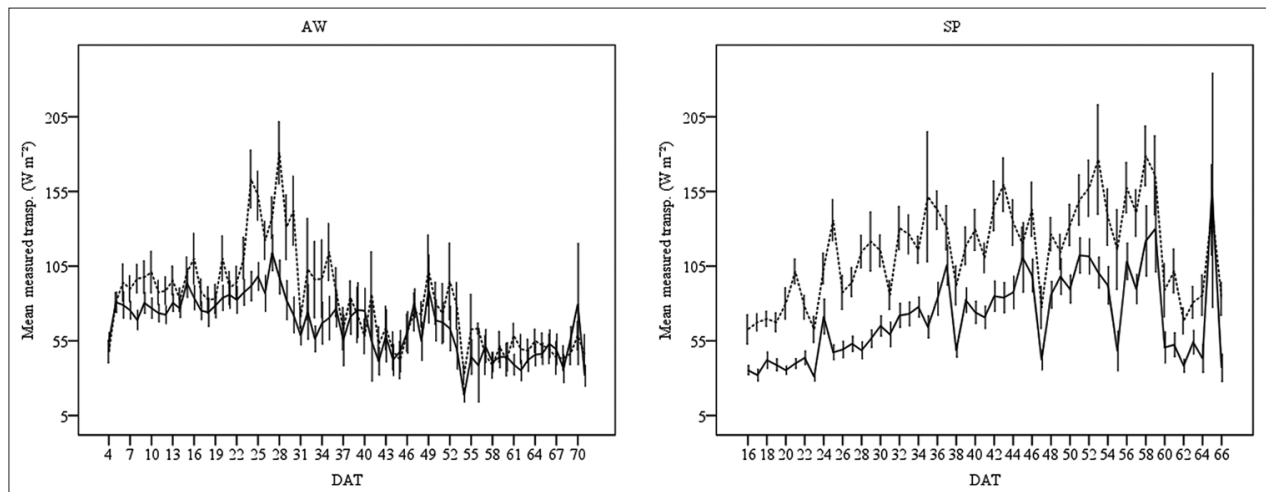

Fig 3. Mean transpiration values ( $\mathrm{W} \mathrm{m}^{-2}$ ) of cucumber plants measured by weighing lysimeters for (2014 autumn-winter crop; AW), left side and (2015 spring crop; SP), right side as affected by cooling, (dotted line-NC and continuous line-C), error bars ( \pm standard error).

all of the predictors examined (Table 6). Moreover, leaf temperature showed the highest value of correlation $\left(\mathrm{R}^{2}\right)$ with transpiration rates.

Taking into account those result, linear regression modelling developed for MIF treatment with equation parameters of the simplified Penman-Monteith model (solar radiation and VPD) as predictors and leaf temperature as a dependant variable, as it is also considered by other researches one of the most promising and valuable plant responses (Naeeni et al., 2014). The coefficient of determination $\left(\mathrm{R}^{2}\right)$ for a number of observations ( $\mathrm{n}=904)$, was 0.72 with $(\mathrm{bi}=-1376.69$, $\mathrm{b} 2=70.694)$ in the case where solar radiation used as a predictor and 0.724 for number of observations ( $\mathrm{n}=$ 1004), with (bi=-3156, b2 $=0.192)$ in the case where VPD used as a predictor (Fig. 5)

Therefore, it seems that by replacing model parameters of incoming solar radiation and VPD with simple 


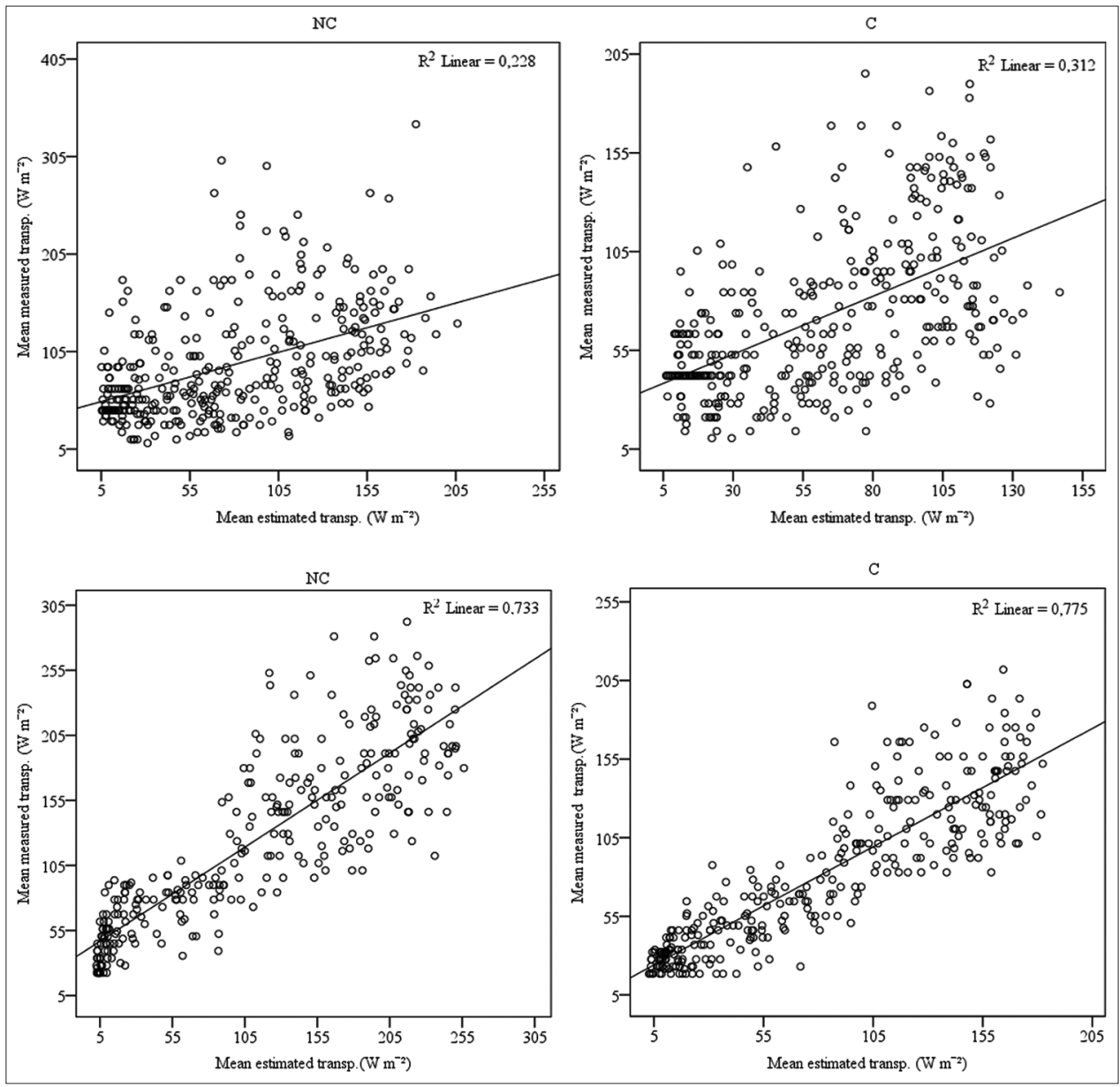

Fig 4. Measured mean transpiration ( $\mathrm{W} \mathrm{m}^{-2}$ ) values of cucumber plants during the (2014 autumn-winter crop; AW) (upper side) plotted against simulated values using experiment data-set (2015 spring crop; SP). Symbols (bottom side) represent measured values during the (2015 spring crop; SP) period plotted against simulated values using experiment data-set from (2014 autumn-winter crop; AW). Linear regression coefficients $\left(R^{2}\right)$ are presented.

Table 3: Mean values ( \pm standard error) of plant transpiration $\left(\mathrm{W} \mathrm{m}^{-2}\right)$ measured by weighing lysimeters for (2014 autumn-winter crop; AW) and (2015 spring crop; SP)

\begin{tabular}{lcccc}
\hline \multicolumn{3}{c}{ AW } & \multicolumn{3}{c}{ SP } \\
\hline DAT & $\mathbf{1 5 - 6 0}$ & $\mathbf{5 0 - 5 5}$ & $\mathbf{1 5 - 6 0}$ & $\mathbf{5 0 - 5 5}$ \\
\hline NC & $104.0(60.8)$ & $86.8(51.1)$ & $130.5(62.5)$ & $171.3(88.1)$ \\
C & $84.7(47.1)$ & $64.9(45.7)$ & $80.1(50.1)$ & $110.2(50.2)$ \\
\hline
\end{tabular}

DAT: days after transplanting; NC: greenhouse compartment without cooling; C: greenhouse compartment with cooling.

observations of leaf temperature in the simplified Penman- Monteith equation (1) may be possible to predict transpiration. The new reformatted equation then will be as below:

$$
\begin{aligned}
\lambda T= & A(1-\exp (-K L A I))(70.694 T-1376.69) \\
& +B L A I(0.192 T-3.156)
\end{aligned}
$$

Where $\mathrm{T}$ is the means crop transpiration rate $\left(\mathrm{kg} \mathrm{m}^{-2} \mathrm{~s}^{-1}\right)$, LAI the calculated leaf area index $\left(\mathrm{m}^{2}\right.$ leaf $\mathrm{m}^{-2}$ ground), $\mathrm{K}$ is the light extinction coefficient and $\mathrm{T}$ is the leaf temperature $\left({ }^{\circ} \mathrm{C}\right)$.

\section{Validation of the reformed model}

The proposed transpiration model was tested, within different greenhouse environmental conditions at 2014 AW and 2015 SP period. Calculated transpiration based on the proposed model was compared with transpiration estimated with the simplified Penman-Monteith equation, as an attempt of validation. The coefficient of determination $\left(\mathrm{R}^{2}\right)$ of an exponential relationship between the transpiration values was $0.974(\mathrm{n}=1001)$ for the $(\mathrm{NC})$ treatment and $0.923(\mathrm{n}=1001)$ for the (C) treatment at 2015 (SP) growing period (Fig. 5).

Even though the model gave satisfactory results of the coefficient for determination $\left(\mathrm{R}^{2}\right)$, of 0.896 for the $(\mathrm{NC})$ treatment and 0.832 for the $(\mathrm{C})$ treatment at a low radiation level during the (AW) growing period, scattering between transpiration values of the two models were greater (data not shown).

Therefore, it seems that estimated transpiration by the use of "real time" measurements of leaf temperature with the 


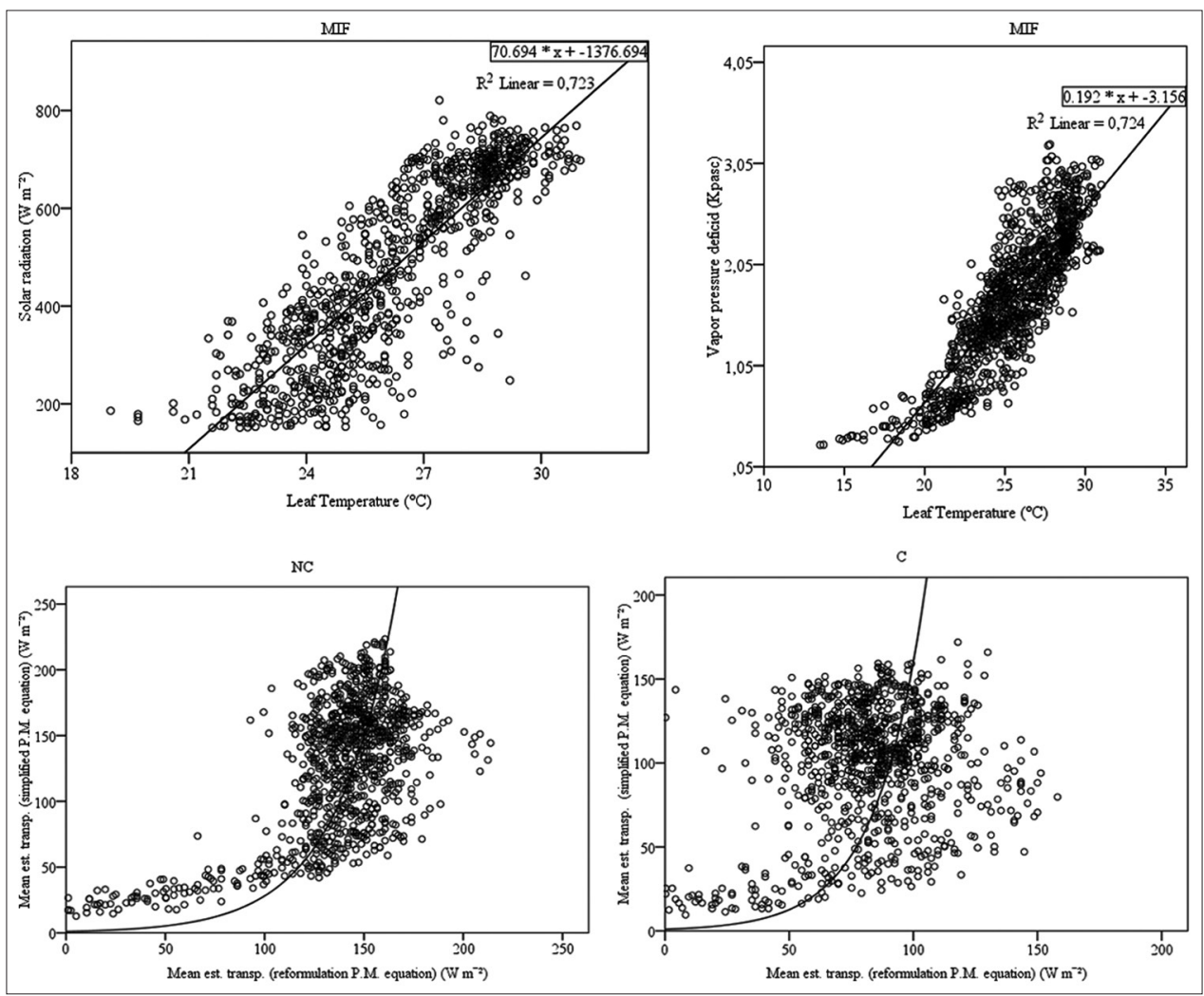

Fig 5. Measured leaf temperature $\left({ }^{\circ} \mathrm{C}\right)$ values of cucumber plants during the 2014 (spring crop; SP) for [Medium Irrigation Frequency (MIF)] treatment plotted against solar radiation $\left(\mathrm{W} \mathrm{m}^{-2}\right)$ and VPD ( $\mathrm{kPasc}$ ) (upper side). Linear regression modeling and coefficients $\left(\mathrm{R}^{2}\right)$ are presented. Calculated transpiration based on the proposed model against transpiration estimated with the simplified Penman-Monteith equation, during the (2015 spring crop; SP, no cooling-NC, cooling-C).

Table 4: Mean values ( \pm standard error) of leaf area index $\left(\mathrm{m}^{2}\right.$ leaf $\mathrm{m}^{-2}$ ground) of treatments for (2014 autumn-winter crop; AW) and (2015 spring crop; SP)

\begin{tabular}{lccccrr}
\hline \multicolumn{7}{c}{ AW } \\
\hline DAT & $\mathbf{1 3}$ & $\mathbf{2 3}$ & $\mathbf{3 3}$ & $\mathbf{4 3}$ & $\mathbf{5 3}$ & $\mathbf{1 3 - 5 3}$ \\
\hline NC & $0.42(0.02)$ & $1.34(0.07)$ & $1.64(0.15)$ & $1.90(0.07)$ & $1.65(0.06)$ & $1.38(0.10)$ \\
C & $0.38(0.03)$ & $1.20(0.08)$ & $1.31(0.13)$ & $1.85(0.05)$ & $1.64(0.08)$ & $1.28(0.10)$ \\
\hline NC & $0.11(0.01)$ & $0.71(0.05)$ & $1.20(0.08)$ & $1.04(0.03)$ & $0.71(0.01)$ & $0.76(0.07)$ \\
C & $0.09(0.00)$ & $0.56(0.04)$ & $0.99(0.10)$ & $0.96(0.04)$ & $0.70(0.03)$ & $0.66(0.06)$ \\
\hline
\end{tabular}

DAT: days after transplanting; NC: greenhouse compartment without cooling; C: greenhouse compartment with cooling.

Table 5: A and B parameters values ( \pm standard error) of the simplified form of Penman-Monteith equation as estimated for (2014 autumn-winter crop; AW) and (2015 spring crop; SP)

\begin{tabular}{lcccccccc} 
& \multicolumn{9}{c}{ AW } & \multicolumn{3}{c}{ SP } & \multicolumn{1}{c}{} \\
\cline { 2 - 8 } & $\mathbf{A}$ & $\mathbf{B}$ & $\mathbf{R}^{2}$ & $\mathbf{n}$ & $\mathbf{A}$ & $\mathbf{B}^{2}$ & $\mathbf{R}^{\mathbf{2}}$ & $\mathbf{n}$ \\
\hline NC & $0.45(0.06)$ & $11.05(5.45)$ & 0.64 & 684 & $0.15(0.03)$ & $40.08(3.56)$ & 0.73 & 912 \\
C & $0.32(0.03)$ & $23.49(4.67)$ & 0.73 & 684 & $0.10(0.03)$ & $50.23(5.91)$ & 0.53 & 912 \\
\hline
\end{tabular}

Parameter A: dimensionless; Parameter $\mathrm{B}: \mathrm{W} \mathrm{m}^{-2} \mathrm{kPa}^{-1} ; \mathrm{R}^{2}$ : correlation coefficient; $\mathrm{n}$ : number of observations; NC: greenhouse compartment without cooling; C: greenhouse compartment with cooling

use of a simple sensor could be an alternative, avoiding the complicity for the estimation of greenhouse vapor pressure deficit. The model seems to work well, even within a different growing period of a year and environmental conditions than those calibrated and could be used in decision support systems in Mediterranean greenhouses.

\section{CONCLUSIONS}

In this study the simplified model (Eq. 1) anticipated for predicting short time transpiration was calibrated and successfully validated. The findings of the current study support that model coefficients, i.e., A and B, respond 
Table 6: Predictors of transpiration for $0.288 \mathrm{Kg} \mathrm{m}^{-2}$ [Medium Irrigation Frequency (MIF)] and for $0.448 \mathrm{Kg} \mathrm{m}^{-2}$ [Low Irrigation Frequency (LIF)] treatment, as estimated for (2014 spring crop; SP)

\begin{tabular}{|c|c|c|c|c|c|c|}
\hline & \multicolumn{3}{|c|}{ MIF } & \multicolumn{3}{|c|}{ LIF } \\
\hline & $\mathbf{R}^{2}$ & $\beta$ & $\mathbf{n}$ & $\mathbf{R}^{2}$ & $\beta$ & $\mathbf{n}$ \\
\hline$R G_{i}\left(\right.$ Watt $\left.m^{-2}\right)$ & $0.76(0.009)$ & 0.87 & 365 & $0.73(0.01)$ & 0.85 & 365 \\
\hline $\operatorname{LT}\left({ }^{\circ} \mathrm{C}\right)$ & $0.87(0.09)$ & 0.93 & 365 & $0.84(0.11)$ & 0.92 & 370 \\
\hline SV $(\mathrm{mm})$ & $0.75(0.55)$ & 0.87 & 377 & $0.72(0.71)$ & 0.85 & 370 \\
\hline ST $\left({ }^{\circ} \mathrm{C}\right)$ & $0.83(0.09)$ & 0.91 & 377 & $0.82(0.10)$ & 0.90 & 370 \\
\hline VPD (kPa) & $0.79(1.8)$ & 0.89 & 377 & $0.79(2.20)$ & 0.88 & 370 \\
\hline
\end{tabular}

$\mathrm{RG}_{\mathrm{i}}$ : inside greenhouse solar radiation; LT: leaf temperature; SV: stem variation; ST: substrate temperature; VPD: greenhouse air vapor pressure deficit; $R^{2}$ : correlation coefficient ( \pm standard error); $\beta$ : beta coefficient; $\mathrm{n}$ : number of observations

differently under prevailing environmental conditions and coincide with the notion that they should be calibrated for each specific situation. This simplified model can be implemented for irrigation control in greenhouses, with the aim of ensuring a more efficient water use in Mediterranean greenhouses. On the other hand, the present study clearly demonstrated that there is a strong connection between leaf temperature and transpiration and irrigation scheduling based on transpiration may be possible to predict even at high irrigation interval cultivations such as the hydroponics cultures, by using plant as an indicator, with the use of a single leaf temperature sensor.

\section{Author's contributions}

The work has been completed under the supervision of C.K, N.K, D.N.; C.K and N.K designed the research plan, organized the study. G.N.: performed research, performed statistical analysis and data interpretation and in assistance with D.N wrote the manuscript which was read and approved by all authors.

\section{REFERENCES}

Baille, M., A. Baille and J. C Laury. 1994. A simplified model for predicting evapotranspiration rate of nine ornamental species vs climate factors and leaf area. Sci. Hortic. 59: 217-232.

Beeson Jr, R. C. 2011. Weighting lysimeters systems for quantifying water used and studies of controlled water stress for crop grown in low bulk density substrates. Agric. Water Manag. 98: 967-976.

Boulard, T. and S. Wang. 2000. Greenhouse crop transpiration simulation from external climate conditions. Agric. Forest Meteorol. 100: 25-34.

Carmassi, G., L. Bacci, M. Bronzini, L. Incrocci, R. Maggini, G. Bellocchi, D. Massa, and A. Pardossi. 2013. Modelling transpiration of greenhouse gerbera (Gerbera jamesonii $\mathrm{H}$. Bolus) grown in substrate with saline water in a Mediterranean climate. Sci. Hortic. 156: 9-18.

De Graaf, R. and M. H. Esmeijer. 1998. Comparing calculated and measured water comsumption in a study of the (minimal) transpiration of cucumbers grown on rockwool. Acta Hortic. 458: 103-112.

Fazlil-Ilahi, W. F. 2009. Evapotranspiration Models in Greenhouse.
M.Sc. Thesis, Wageningen Agricultural University. The Netherlands, p. 47.

Feng, Z., S. Wan, Y. Kang, and L. Shiping. 2017. Drip fertigation regime for potato on sandy soil. Emirates J. Food Agric. 2017. 29(6): 476-484.

Fulcher, F. A., W. J. Buxton and L. R. Geneve. 2012. Developing a physiological-based, on-demand irrigation system for container production. Sci. Hortic. 138: 221-226.

Helmer, T., D. L. Ehret and S. Bittman. 2005. Crop assist, an automated system for direct measurement of greenhouse tomato growth and water use. Comput. Electron. Agric. 48: 198-215.

Juárez-Maldonado, A., A. Benavides-Mendoza, K. De-Alba-Romenus, and A. B. Morales-Díaz. 2014. Estimation of the water requirements of greenhouse tomato crop using multiple regression models. Emirates. J. Food Agric. 26 (10): 885-897.

Katsoulas, N., C. Kittas, G. Dimokas and C. Lykas. 2006. Effect of irrigation frequency on rose flower production and quality. Biosyst. Eng. 93(2): 237-244.

Kittas, C. 1990. Solar radiation of a greenhouse as a tool to its irrigation control. Int. J. Energ. Res. 14: 881-892.

Kittas, C., N. Katsoulas and A. Baille. 1999. Transpiration and canopy resistance of greenhouse soilless roses: Measurements and modeling. Acta Hortic. 507: 61-68.

Körner, O. and H. Challa. 2003. Process-based humidity control regime for greenhouse crops. Comput. Electron. Agric. 39: 173-192.

Liu, H. J, S. Cohen, J. Tanny, J. H. Lemcoff and G. Huang. 2008. Estimation of banana (Musa sp.) plant transpiration using a standard $20 \mathrm{~cm}$ pan in a greenhouse. Irrigation Drainage Syst. 22: 311-323

Luo, W., H. F. Zwart, J. Dail, X. Wang, C. Stanghellini and C. Bu. 2005. Simulation of greenhouse management in the subtropics, Part I: Model validation and scenario study for the winter season. Biosyst. Eng. 90(3): 307-318.

Medrano, E., P. Lorenzo, M. C. Sánchez-Guerrero and J. I. Montero. 2005. Evaluation and modeling of greenhouse cucumber-crop transpiration under high and low radiation conditions. Sci. Hortic. 105:163-175.

Meijer, J., G. P. A. Bot, C. Stanghellini and A. J. U. Cate. 1985. Development and application of a sensitive, high precision weighting lysimeter for use in greenhouses. J. Agr. Eng. Res. 32: 321-336.

Montero, J. I., A. Anton, P. Muñoz and P. Lorenzo. 2001. Transpiration from geranium grown under high temperatures and low humidities in greenhouses. Agric. Forest Meteorol. 107: 323-332.

Morille, B., C. Migeon and P. E. Bournet. 2013. Is the Penman-Monteith model adapted to predict crop transpiration under greenhouse conditions? Application to a New Guinea Impatiens crop. Sci. Hortic. 152: 80-91.

Naeeni, A. E., E. M. Esfahani, M. B. Harchegani, M. Jafarpour and M.Golabadi. 2014. Leaf temperature as an index to determine the irrigation interval. Plant Physiol. 9-1: 89-95.

Pollet, S., P. Bleyaert and R. Lemeur. 2000. Application of the penman-monteith model, to calculate the evapotranspiration of head lettuce (Lactuca sativa L. var. Capitata) in glasshouse conditions. Acta Hortic. 519: 151-162.

Razzak, A., W. Allahi, A. Ibrahimi, M. Alenazi and A. Alsadon. 2016. Response of cherry tomato to irrigation levels and fruit pruning under greenhouse conditions. J. Agr. Sci. Tech. 18: 1091-1103.

Rouphael, Y., M. Cardarelli, E. Rea and G. Colla. 2004. Modelling the transpiration of a greenhouse zucchini crop grown under a Mediterranean climate using the Penman-Monteith equation and 
its simplified version. Aust. J. Agric. Res. 55: 931-937.

Savvas, D., G. Gianquinto, Y. Tuzel and N. Gruda. 2013. Soilless Culture. Good Agricultural Practices for greenhouse vegetable crops, FAO: 303-354.

Schmidt, C.D.S., F.A.C. Pereira, A.S. Oliveira, J.F.G. Júnior and L.M. Vellame. 2013. Design, installation and calibration of a weighing lysimeter for crop evapotranspiration studies. Water Res. Irrig. Manag. 2:77-85.

Schröder, F. G. and J. H. Lieth. 2002. Irrigation control in hydroponics. In: Savvas, D. and H. C Passam (Ed.), Hydroponic Production of Vegetables and Ornamentals. Embryo Publications, Athens, Greece, p. 263-298.

Steppe, K., D. J. W. Pauw and R. Lemeur. 2008. A step towards new irrigation scheduling strategies using plant- based measurements and mathematical modeling. Irrigation Sci. 26: 505-517.

Ton, Y. and M. Kopyt. 2003. Phytomonitoring: A bridge from sensors to information technology for greenhouse control. Acta Hortic. 614: 639-644.

Tsirogiannis, I., N. Katsoulas and C. Kittas. 2010. Effect of irrigation scheduling on gerbera flower yield and quality. Hortic. Sci. 45:265-270.
Varma, V. and M.A Osuri. 2013. Black Spot: A platform for automated and rapid estimation of leaf area from scanned images. Plant Ecol. 214(12): 1529-1534.

Villarreal-Guerrero, F., M. Kacira, E. Fitz-Rodríguez, C. Kubota, G. A. Giacomelli, R. Linker and A. Arbel. 2012. Comparison of three evapotranspiration models for a greenhouse cooling strategy with natural ventilation and variable high pressure fogging. Sci. Hortic. 134: 210-221.

Yang, X., Short, J. H., Fox, R. D. and W. L. Bauerle. 1989. The microclimate and transpiration of a greenhouse cucumber crop. Am. Soc. Agric. Eng. 32(6): 2143-2150.

Yang, X., T. M. Short, R. D. Fox and W. L. Bauerle 1990. Transpiration, leaf temperature and stomatal resistance of a greenhouse cucumber crop. Agric. Forest Meteorol. 51: 197-209.

Zhao, S., Q. Wang, Y. Yao, S. Du, C. Zhang, J. Li and J. Zhao 2016. Estimating and validating wheat leaf water content with three MODIS spectral indexes: A case study in ningxia plain, China. J. Agric. Sci. Technol. 18: 387-39.

Zi-kun, Z., L. Shi-qi, L. Su-hui, and H. Zhi-jun. 2010. Estimation of cucumber evapotranspiration in solar greenhouse in northeast China. Agr. Sci. China. 9(4): 512-518. 